\title{
Sustainability of health care financing in the western Balkans: an overview of progress and challenges
}

\begin{abstract}
This article explores the major challenges to the sustainability of health sector financing in the countries of the western Balkans - Albania, Bosnia and Herzegovina, the Former Yugoslav Republic of Macedonia, Montenegro, Serbia and the province of Kosovo. It focuses on how the incentives created by the different elements of the healthcare financing system affect the behaviour of healthcare providers and individuals, and the resulting inefficiencies in revenue collection and expenditure containment. The article analyses patterns of healthcare expenditure, finding that there is some evidence of cost containment, but that current expenditure levels - while similar to that in EU countries as a share of GDP - are low in per capita terms while the fiscal space to increase expenditures is extremely limited. It also examines the key drivers of current health care expenditure and the most significant barriers to revenue generation, identifying some key health reforms that countries in the sub-region could consider in order to enhance the efficiency and sustainability of their health systems. Data are drawn from international databases, country institutions and household surveys.
\end{abstract}

Keywords: health care reform, fiscal sustainability of health sector, sources of health care revenues, health insurance funds, social contribution rates and policies, efficiency of health expenditure, national health accounting systems, supply of medical facilities

\section{Introduction}

The five western Balkan countries - Albania, Bosnia and Herzegovina, Former Yugoslav Republic (FYR) of Macedonia, Montenegro and Serbia - and the province of Kosovo ${ }^{1}$ have undergone significant transitions in the past decade or two, which have been complicated by a series of regional conflicts. After an initial phase focused on macroeconomic stabilisation and reconstruction, reforms are now focusing on enhancing economic growth, promoting employment generation and encouraging the containment and efficiency of public spending. The countries' shared aspiration to join the European Union (EU) exerts an important influence on policy decisions.

In the health sector, the main challenge is to continue to make progress towards achieving health system objectives, namely improving the health status of the popula-

1 At the time this paper was written, Kosovo was a province of Serbia under the autonomous administration of the United Nations. For the purposes of this paper, it is treated as a separate unit of analysis. 
tion and providing protection against the financial costs of illness, while ensuring the financial sustainability of the health sector.

This article explores the major challenges to the sustainability of health sector financing in the western Balkans, both on the revenue and the expenditure side, and identifies measures that can be taken to enhance it. It focuses on those elements that are endogenous to the health care financing system, and that are amenable to improvement through government-led reforms, rather than exogenous elements such as demographic change and fiscal pressures. In so doing, it examines the incentives created by the different elements of the health care financing system (such as the revenue collection system and the provider payment mechanism) and the effect that these incentives have on the behaviour of health care providers, firms and individuals, and the resultant inefficiencies. The central thesis is that more efficient management of revenue collection and spending will be needed in the future, even though western Balkans states have succeeded in containing the growth in public expenditure on health during the past few years, if countries are to steer their health systems towards attaining their objectives while meeting the obligation of fiscal sustainability.

The structure of the article is as follows: after describing the geographical scope of the analysis and the limitations of the data, the main patterns and historical trends in the sources of health care financing are presented and the key challenges that health systems face in ensuring sufficient revenue generation are discussed. Then, current and past expenditure patterns are described and the effects of the structure of the health care financing system on the magnitude and efficiency of health expenditures are explored. The article concludes by summarising some of the key health sector reforms that countries in the western Balkans could consider in order to enhance the effectiveness and sustainability of their health systems.

\section{Geographical scope, data sources and limitations}

\section{Geographical scope}

This article defines the western Balkans as the five south-east European countries of Albania, Bosnia and Herzegovina, the Former Yugoslav Republic of Macedonia, Montenegro and Serbia, and the province of Kosovo. ${ }^{2}$ With the exception of Albania, all of these countries were part of the former Socialist Federal Republic of Yugoslavia (SFRY).

Throughout the article, comparisons will be made with financing and expenditure patterns in the EU-15 $5^{3}$ and EU-12 4 countries. Explicit comparisons will also be made with Croatia and Slovenia. They are useful comparators because they were originally

2 This definition of the western Balkans reflects the World Bank's operational classification of the sub-regions of Europe and Central Asia.

3 EU-15 countries include all those that had joined the EU by 1995, namely Austria, Belgium, Denmark, Finland, France, Germany, Greece, Ireland, Italy, Luxembourg, the Netherlands, Portugal, Sweden, the United Kingdom and Spain.

4 EU-12 countries include those that joined the EU from May 2004 onwards, namely Bulgaria, Cyprus, the Czech Republic, Estonia, Hungary, Latvia, Lithuania, Malta, Poland, Romania, the Slovak Republic and Slovenia. 
part of SFRY, seceding in 1991, and have shared common aspirations concerning EU membership. ${ }^{5}$

\section{Data sources}

The data used in this report are drawn from a number of sources:

a. international databases: the World Bank's World Development Indicators 2007 database (WDI, 2007) is the main source of health expenditure data. ${ }^{6}$ For certain estimates that are not available in the WDI database, the World Health Organization's (WHO) Health for All 2007 database (HFA-DB 2007) is used. Most of the information on revenue sources is obtained from the WHO National Health Accounts (NHA) database.

b. country institutions: this article also relies on information provided to the World Bank by country institutions such as ministries of health, ministries of finance, statistical institutes and institutes of public health. Some of this information has been published in World Bank reports, including poverty assessments, country and sector studies, and public expenditure and institutional reviews. These information sources are particularly valuable for data on Serbia, Montenegro and Kosovo, for which revenue and expenditure information is not yet available in the major databases.

c. household surveys: data on private out-of-pocket expenditure are mainly drawn from household surveys, conducted by governments or by statistical or international organisations, often with the support of the World Bank. These include the Living Standards and Measurements Survey (LSMS) and the Household Budget Survey (HBS).

\section{Data limitations}

All of these sources are subject to certain limitations with respect to data availability and reliability, many of which are well-known and typical of the particular mode of data collection. In addition, the following limitations are of particular relevance to the data of the sub-region:

a. accuracy of population estimates: population estimates, and thus all per capita estimates, are subject to a high degree of inaccuracy owing to mass migration movements associated with sub-regional conflicts, as well as an incomplete registration of births and deaths.

b. political status of Serbia, Montenegro and Kosovo: separate data for Serbia and Montenegro are not yet available in most international databases since it is only in 2006 that Montenegro gained independence. There is also no information available for Kosovo in these databases due to its current status as an autonomous province. Data for Serbia, Montenegro and Kosovo, then, are predominantly drawn from World Bank documents such as health sector notes and public expenditure and institutional reviews.

5 Slovenia is already a member of the EU and Croatia, having signed a Stabilisation and Association Agreement with the EU in 2005, is advancing towards full membership.

6 Most of the WDI data are, in turn, derived from the latest WHO estimates, which are published in the WHO's World Health Report 2006, and then supplemented by published and unpublished World Bank and International Monetary Fund (IMF) data. 
c. data vintage: for most analyses, this report uses 2004 data, which is the latest year for which validated data are available in most international databases. If earlier or later estimates are used, this is stated.

d. consistency of estimates across sources: for some indicators, the international databases contain different estimates for the same year. In addition, the EU, EU-15 and EU-12 aggregate estimates that are produced by the WHO HFA-DB 2007 and World Bank WDI 2007 databases sometimes differ, since the former uses population weights in compiling its estimates while the latter bases its weights on the denominator. In the event of inconsistencies across databases, we favoured the estimates in World Development Indicators 2007 over other databases and estimates in World Bank publications over estimates in the publications of other institutions.

Owing to these limitations, data should be interpreted only as indicative of broad trends and of major differences across countries, rather than as providing precise quantitative measures of those differences, even though they are drawn from the sources thought to be the most accurate.

\section{Ensuring sufficient revenues}

The relative importance of payroll taxation and general revenues in the financing mix is one of the most common distinctions made between health care systems. In pure Bismarckian systems, the dominant sources of financing are employer and employee contributions, levied as a proportion of payroll, and pooled in social health insurance funds. At the other end of the spectrum, pure Beveridge systems are funded from general revenues with universal entitlement to a fairly comprehensive range of services, at least in western Europe.

The health system of the former Yugoslavia, referred to as the Stampar model, was unique in eastern Europe because it was funded from compulsory social insurance contributions rather than the state budget. ${ }^{7}$ This financing mode persists in the new states and social health insurance is the dominant form of health financing in Macedonia, Serbia, Montenegro, and Bosnia and Herzegovina. The heritage of Albania's health care system is very different. Based on the former Soviet Semashko model, it was historically funded directly from the central government budget, with central health allocations for different health inputs and for each health care institution made according to population-based norms. Health insurance was only introduced in 1995 and does not play as prominent a role in health financing as in other countries of the sub-region.

Social health insurance, as it is implemented in the sub-region, is similar to social health insurance in most of the EU-15 countries.

In the countries of the former Yugoslavia, there are publicly-financed and administered extra-budgetary health insurance funds that are responsible for overseeing and implementing both compulsory and any voluntary health insurance schemes. One characteristic of the systems is a purchaser-provider split - health insurance funds

7 The Štampar model, named after the Croatian specialist in social medicine, Andrija Stampar, emphasised primary health care and community-based medicine, encouraging family practice as a recognised specialisation of medicine. 
collect and pool insurance contributions ${ }^{8}$ and then contract with public, and sometimes private, providers to deliver health services. In Albania, on the other hand, the purchaser-provider split is still evolving. Albania's Ministry of Health exercises considerable control as both a financier and provider of health services: health services are directly financed through the state budget based on inputs (e.g. salaries); local governments administer primary health care; and the health insurance fund (a quasiautonomous public agency) is slowly being granted control over health financing and contracting.

Another characteristic of the systems of the sub-region is the notion of a single payer - the national health insurance fund is the only purchaser in the health care system, which is intended to lower administrative costs and enable it to leverage its monopsonistic power to purchase services from health care providers.

\section{Sources of health care revenues}

Recognising that, eventually, with the exception of donor funds, all health care funding originates with the individual, three main financing sources can be identified in the health sector. These include social health insurance (i.e. compulsory contributions in the form of payroll taxes); governmental revenues (in the form of direct and indirect taxes); and out-of-pocket payments (paid directly by the patient at the point of service). Out-of-pocket expenditures may be in the form of co-payments or co-insurance - paid-for services partially covered by health insurance and designed to discourage unnecessary health care consumption - or in the form of full cash payments by the uninsured or for services that lie outside the benefit package. In some countries, out-of-pocket expenditures may be inflated by informal payments to health care providers. Informal payments are usually defined as payments in cash or kind that recipients are not authorised to receive under the conditions of their contract or under the statutes of the governing bodies of their parent organisations (Chawla, 2005) but, in some places, informal payments can also take the form of genuine gifts given by patients to providers in appreciation of their services.

A fourth potential source of financing is voluntary health insurance which can be provided by the public insurance provider or by private insurance companies. Voluntary health insurance may be of the substitutive type, where it is offered as an alternative to mandatory social health insurance for at least a portion of the population; or complementary, to cover the cost of co-payments; or supplementary, to cover health care services not included in the standard benefits package. Donor funds are a fifth source of financing, but its share of total health care financing in the sub-region is small and has been declining.

Systems that rely more heavily on public funding tend to do better at attaining health system objectives, such as financial protection, equity in finance and equity in utilisation (WHO/EURO, 2006). The share of public health care financing, including both social health insurance and general revenues, in total health care revenues is substantial in at least some countries of the sub-region and, in 2005, was equivalent to

8 In Bosnia and Herzegovina, the collection and pooling functions are separated and performed by different institutions: the national taxation authority and some cantons collect contributions; while there are multiple health insurance funds at different levels of government where contributions are pooled. 
around $70 \%$ in Macedonia as well as in Serbia and Montenegro. Still, this was less than the share of public resources in the comparator countries of Croatia and Slovenia ( $81 \%$ and $77 \%$ respectively). Almost all remaining health care expenditure is in the form of private out-of-pocket expenditures. In Albania and in Bosnia and Herzegovina, more than half of total health care financing is in the form of out-of-pocket payments made by households (see Figure 1), potentially rendering the health systems in these countries less accessible to the poor.

\section{Figure 1 - Sources of health care financing, 2005}

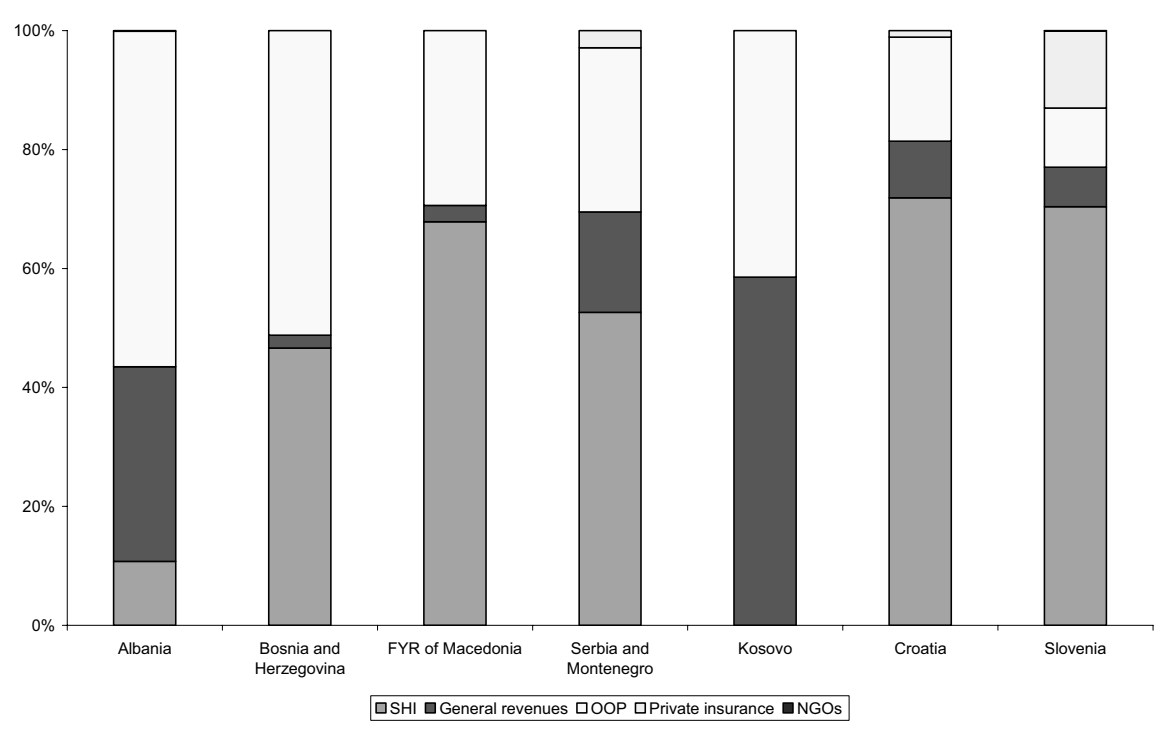

Source: WHO NHA database ${ }^{9}$

Note: Exact figures are provided in Table 8 in the Appendix; the definition of 'private insurance' includes all pre-paid, private risk-pooling plans; Kosovo data are for 2004 and the figure does not show the $2.1 \%$ of donor funding received in that year.

In all the countries of the former Yugoslavia, payroll taxation is a major source of financing and most public expenditure on health flows through the health insurance funds (see Table 1). This includes both monies collected as payroll contributions to the health insurance funds as well as transfers to these funds from extra-budgetary funds, e.g. from the pensions and unemployment funds to cover the health insurance contributions of pensioners and the unemployed. In 2005, according to WHO National Health Accounts data, this was equivalent to about $96 \%$ of public health sector resources in both FYR of Macedonia and Bosnia and Herzegovina. In Serbia and

9 Note that these are estimates and, with the exception of Serbia, none of the countries in the sub-region have developed and institutionalised a National Health Accounts system. 
Montenegro, the share was a little lower, at $76 \% .^{10}$ These percentages are in the same range as the share of social health insurance in public revenues in Croatia and Slovenia, the two republics of ex-Yugoslavia that have made most progress in health sector financing reform. In Albania, despite a mandatory contributory health insurance scheme, social health insurance funded only $25 \%$ of public health sector expenditure, with the rest coming from general revenues. Kosovo has drafted a health insurance law, but there is not yet a health insurance fund in the country and all health expenditure is financed from the general budget and user fees, with some additional, but declining, off-budget donor support (equivalent to $2.1 \%$ of total health expenditure in 2004). ${ }^{11}$

Table 1 - Share of public health sector revenues from social health insurance contributions and general revenues, 2005

\begin{tabular}{|l|c|c|c|}
\hline & $\begin{array}{c}\text { Social health } \\
\text { insurance }\end{array}$ & General revenues & Total \\
\hline Albania & 24.8 & 75.2 & 100 \\
\hline Bosnia and Herzegovina & 95.6 & 4.4 & 100 \\
\hline FYR of Macedonia & 96.1 & 3.9 & 100 \\
\hline Serbia and Montenegro & 75.7 & 24.3 & 100 \\
\hline Kosovo & 0 & 100 & 100 \\
\hline Croatia & 88.3 & 11.7 & 100 \\
\hline Slovenia & 91.4 & 8.6 & 100 \\
\hline
\end{tabular}

Source: WHO NHA database

Private, voluntary health insurance is not well-developed in the western Balkans. Serbia is the only country in the sub-region where private insurance schemes constitute a significant, if small, share $(3 \%)$ of total health care revenues. There, the Health Insurance Act of 2005 allowed for the development of voluntary health insurance of a substitutive or complementary type, but the number of subscribers is small and concentrated in large cities. A limited number of commercial insurers are also active in Bosnia and Herzegovina, while FYR of Macedonia and Montenegro have a legal framework in place that will facilitate the emergence of an insurance market (Langenbrunner et al, forthcoming). In all countries, however, there are some major obstacles to the development of private voluntary health insurance. Most prominent among these are the generous benefit packages offered by compulsory health insurance, the fairly limited number of private providers that can offer alternative care, and low co-

10 According to World Bank estimates, 90 per cent of public health expenditure in Serbia in 2005 was in the form of payroll contributions paid to the HIF.

11 Discussion is ongoing as to whether social health insurance would be the best type of financing for the health sector in Kosovo. 
payments - all of which reduce the incentives to develop supplementary and complementary insurance plans.

Over time, there have been marked shifts in the composition of revenues. These shifts have not, however, exhibited a uniform pattern across countries (see Figure 2) and it is not possible to identify a particular trend. In Albania, the share of out-ofpocket expenditures has fallen slightly while the share of social health insurance has grown. In Bosnia and Herzegovina, the share of general revenues has dwindled while the shares of social health insurance and out-of-pocket expenditures have grown by similar amounts. The opposite pattern is observed in Serbia and Montenegro where, following a fairly volatile period (due, in part, to the conflicts in the region and, in part, to health sector reforms), general revenues had, by the end of the decade, become a far more important source of financing than they were ten years earlier, at the expense of the role played by social health insurance. The emerging importance of private health insurance as a source of financing in Serbia is also captured by the data. There has been very little change in the composition of financing in FYR of Macedonia.

\section{Figure 2 - Trends in the composition of revenues}
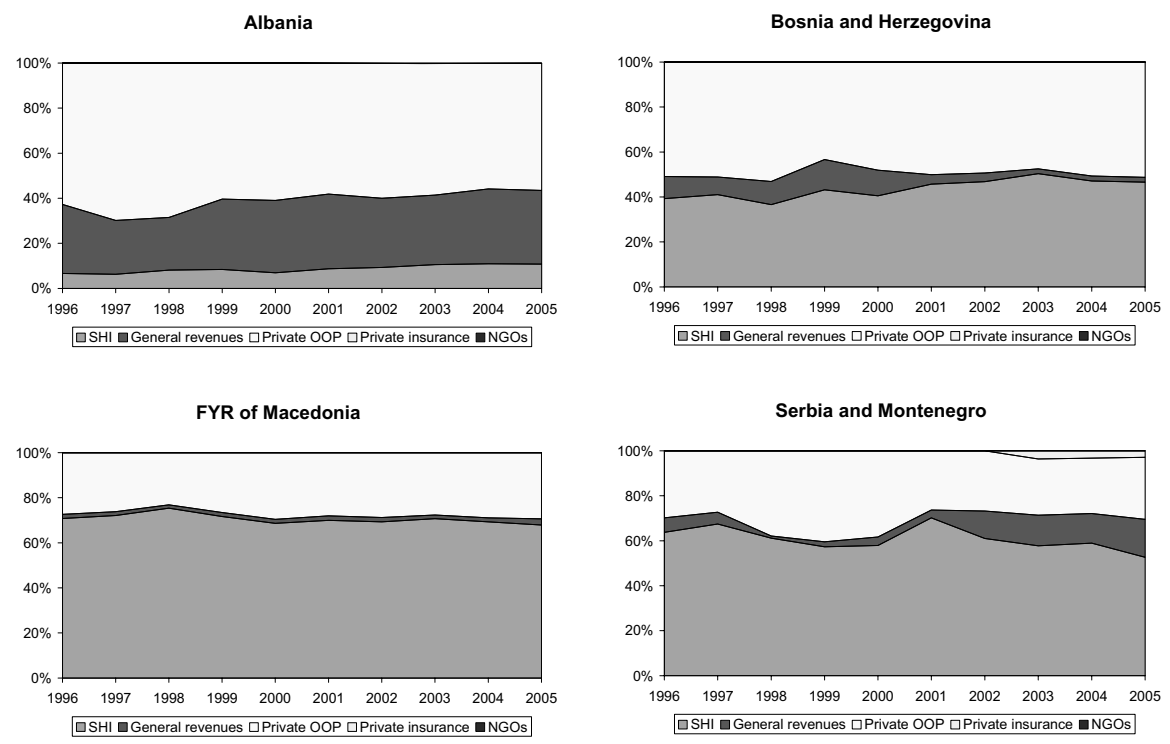

Source: WHO NHA database

As with most social health insurance schemes elsewhere in the world, contributions to health insurance funds in the sub-region are not related to individual or group risk but are levied on earned income. They are compulsory for most employed groups and are typically shared between employee and employer. The greatest share of health care funding is collected through compulsory payroll taxation, but there is also a direct transfer of contributions from the state budget to the health insurance funds on 
behalf of particular categories of people who are exempt from making contributions, as well as to finance special programmes and the administrative costs of the Ministry of Health.

In the countries of the former Yugoslavia, where payroll contributions account for at least three-quarters of health sector revenues, health insurance contribution rates paid by formally-employed workers are high, between $15 \%$ and $17 \%$ of payroll (see Table 2). Albania, where payroll taxes account for only $25 \%$ of health sector revenues, is entirely different: health insurance contributions amount to only $3.4 \%$ of wages, shared equally between employer and employee. This pattern reflects Albania's heritage: countries of the former Soviet Union typically set the level at around 2$4 \%$ of payroll.

There is no consistent pattern in the sub-region regarding the employer-employee share of the burden of taxation. Both are equally taxed in Albania, Montenegro and Serbia; in FYR of Macedonia the employer pays the total cost of the health insurance contribution; and in both entities of Bosnia and Herzegovina, most of the tax burden falls on the employee. Farmers and the self-employed tend to face lower contribution rates than salaried workers in the public and private sectors.

Many categories of labour force participants are exempt from paying contributions. The state budget transfers money to the health insurance funds to cover certain vulnerable groups such as people with disabilities and war veterans. The unemployed and pensioners either have their insurance contributions paid on their behalf by the unemployment and pensions funds or else they are covered by budgetary transfers.

\section{Challenges ahead}

In all countries of the sub-region (with the exception of Kosovo), it is the health insurance fund that pools health revenues, regardless of whether the source of those revenues are payroll taxation or general taxation (i.e. central budget transfers). The flow of revenues from these primary revenue streams to the health insurance fund has been unreliable and, together with escalating expenditures, has resulted in repeated annual deficits and chronic arrears (see below). This is due to a number of factors. Some factors are related to the flow of contributions from employer- and employee-funded health insurance and include the labour market structure (specifically, widespread unemployment and a large informal sector, which narrow the contributions base); the large number of categories of the population that are formally exempt from making contributions; and the evasion of contributions by those who are legally obliged to pay, partly due to poor collection enforcement mechanisms. In addition, budgetary transfers to the health insurance funds to cover, among other things, the contributions of exempt populations are not always sufficient. Another factor affecting revenue flows to the health sector is the fees and charges levied at the point of service: users tend to be charged low co-payments; many categories of people are exempt from making co-payments; and a fairly wide range of health services do not have co-payments associated with them.

\section{Limited formal employment growth and high levels of informal employment}

The sustainability of health care financing is affected by the structure of the labour market. Social health insurance works best in economies with high levels of formal 
employment, and thus large payroll contributions bases, and efficient administrative systems that facilitate the payment of contributions.

Table 2 - Health insurance contribution rates

\begin{tabular}{|c|c|c|c|c|}
\hline & $\begin{array}{l}\text { Year } \\
\text { started }\end{array}$ & $\begin{array}{l}\text { Salaried worker } \\
\quad \text { (employer: } \\
\text { employee share) }\end{array}$ & Self-employed & $\begin{array}{l}\text { Non-active and } \\
\text { contributions- } \\
\text { exempt groups }\end{array}$ \\
\hline Albania & 1995 & $\begin{array}{c}3.4 \% \text { of payroll } \\
(1.7: 1.7)\end{array}$ & $\begin{array}{l}3-7 \% \text { of statutory } \\
\text { minimum wage, de- } \\
\text { pending on } \\
\text { urbanicity }\end{array}$ & Central budget \\
\hline \multicolumn{5}{|c|}{ Bosnia and Herzegovina } \\
\hline - Federation & 1997 & $\begin{array}{c}17 \% \text { payroll } \\
(4: 13)\end{array}$ & $\begin{array}{l}15 \% \text { of cadastre } \\
\text { revenue }\end{array}$ & $\begin{array}{l}\text { Central budget, } \\
\text { pensions and un- } \\
\text { employment funds }\end{array}$ \\
\hline $\begin{array}{l}\text { Republika } \\
\text { Srpska }\end{array}$ & 1999 & $\begin{array}{c}15 \% \text { of payroll } \\
(0: 15)\end{array}$ & $\begin{array}{l}15 \% \text { of cadastre } \\
\text { revenue }\end{array}$ & $\begin{array}{l}\text { Central budget, } \\
\text { pensions and un- } \\
\text { employment funds }\end{array}$ \\
\hline FYR of Macedonia & 1991 & $\begin{array}{c}9.2 \% \text { of payroll } \\
(9.2: 0)\end{array}$ & $9.2 \%$ of income & Central budget \\
\hline Montenegro & 1993 & $\begin{array}{c}15 \% \text { of payroll } \\
(7.5: 7.5)\end{array}$ & $\begin{array}{l}13.5 \% \text { of main } \\
\text { wage }\end{array}$ & $\begin{array}{l}\text { Pensioners: } 19 \% \text { of } \\
\text { net pension; } \\
\text { unemployed: } 9.7 \% \\
\text { of unemployment } \\
\text { benefit but, in } \\
\text { practice, } 7.5 \% \text {; } \\
\text { others: central } \\
\text { budget }\end{array}$ \\
\hline Serbia & 1992 & $\begin{array}{c}15.92 \% \text { of payroll } \\
(7.95: 7.97)\end{array}$ & $\begin{array}{l}14.4 \% \text { of net wage; } \\
\text { farmers: } 4 \% \text { of } \\
\text { property tax }\end{array}$ & $\begin{array}{l}\text { Pensioners } 12.3 \% \\
\text { of net pensions; } \\
\text { others: central } \\
\text { budget, equal to } \\
15.95 \% \text { of average } \\
\text { wages }\end{array}$ \\
\hline Croatia & 1993 & $\begin{array}{c}15 \% \text { of payroll } \\
(15 \%: 0)\end{array}$ & $\begin{array}{l}18 \% \text { of income; } \\
\text { farmers: } 15 \% \text { of in- } \\
\text { come if in the VAT } \\
\text { system, or } 7.5 \% \text { of } \\
\text { estimated income } \\
\text { based on land own- } \\
\text { ership }\end{array}$ & $\begin{array}{l}18 \% \text { of gross } \\
\text { pension and other } \\
\text { benefits, plus } \\
\text { central budget and } \\
\text { county budgets }\end{array}$ \\
\hline Slovenia & 1993 & $13.25 \%$ of payroll & $13.25 \%$ of income & Central budget \\
\hline
\end{tabular}

Source: Langenbrunner et al. (forthcoming)

Unemployment rates are high in all countries of the sub-region, except Albania, and employment tends to be of a long-term nature. No country approaches the target 
of a 70\% employment rate outlined in the European Employment Strategy. Rather, a large share of the active labour force works in the informal sector, where contributions to health insurance are not made. Another segment of the population is formally self-employed and, therefore, responsible for making their own contributions, but compliance among this group is not effectively enforced. It is particularly difficult to collect contributions from farmers, and especially subsistence farmers, because of the difficulties associated with assessing their incomes. The result is that active health insurance contributors often account for a relatively small share of the active labour force.

In economies with this labour market structure, and where the link between entitlement to services and the payment of contributions is weak, a reliance on payroll taxes is likely to result in the demand for services exceeding the resources that are available to finance them.

Table 3 - Labour market indicators, western Balkans, 2004

\begin{tabular}{|c|c|c|c|c|c|}
\hline & $\begin{array}{c}\text { Partici- } \\
\text { pation } \\
\text { rate }\end{array}$ & $\begin{array}{l}\text { Employ- } \\
\text { ment rate }\end{array}$ & $\begin{array}{l}\text { Unemploy- } \\
\text { ment rate }\end{array}$ & $\begin{array}{c}\text { Long-term } \\
\text { unemploy- } \\
\text { ment }^{\mathrm{a}}\end{array}$ & $\begin{array}{l}\text { Informal } \\
\text { employ- } \\
\text { ment rate }\end{array}$ \\
\hline Albania & $63.7 \%$ & $60.1 \%$ & $5.6 \%$ & $68.4 \%$ & $76 \%$ \\
\hline Bosnia and Herzegovina & $59 \%$ & $46 \%$ & $22 \%$ & & $42 \%$ \\
\hline Kosovo & n.a. & n.a. & $50 \%{ }^{\mathrm{c}}$ & n.a. & n.a. \\
\hline FYR of Macedonia & $51.2 \%$ & $32 \%$ & $37.2 \%$ & $84.5 \%$ & n.a. \\
\hline Montenegro & $65.1 \%$ & $40.6 \%$ & $23 \%$ & $85 \%$ & $27 \%$ \\
\hline Serbia & $66.6 \%$ & $53.5 \%$ & $19.5 \%$ & $71 \%$ & $35 \%$ \\
\hline \multicolumn{6}{|c|}{$\begin{array}{l}\text { a. The long-term unemployment rate is the percentage of the unemployed that have been unem- } \\
\text { ployed for } 12 \text { months or longer. } \\
\text { b. Definitions of the informal employment rate vary by country. } \\
\text { c. The official unemployment rate in Kosovo is around 50\%, but World Bank estimates that take } \\
\text { into account seasonal and informal employment place the unemployment rate within the } \\
23 \%-33 \% \text { range. }\end{array}$} \\
\hline
\end{tabular}

Source: ILO for Macedonia; World Bank estimates for other countries

Note: Most estimates are based on household surveys; for Montenegro, data are based on registered unemployed; all Kosovo figures should be treated with scepticism due to the poor availability of data.

\section{Limited scope to raise social health insurance contributions}

In general, financial planning with respect to contribution rates is poor and contribution rates are still not set according to an actuarial analysis of expected costs and revenues for the insured population. Rather, contribution rates tend to be based on a combination of estimates of desired revenues (which may or may not reflect the actual revenue that can feasibly be collected, given the challenges outlined above) and an assessment of the political acceptability of adding to an already high tax burden (Langenbrunner et al, forthcoming). 
There does not appear to be much scope to raise health insurance contributions in future. With the exception of Albania, contribution rates are already very high and comparable to those in the EU-15. The situation is further constrained since other forms of payroll taxation are also high. In Serbia, for example, there is an effective $36 \%$ social tax on wages, including health insurance contributions of $12 \%$, pensions contributions of $22 \%$ and unemployment contributions of $1.5 \%$.

High labour taxes are a brake on employment expansion. Indeed, one question that arises is whether the current high unemployment levels are partly the result of these high levels of payroll taxation. In theory, and in the long run, a tax on wages would be shifted to employees, but in countries where product and labour markets are not very competitive, employers may not be able to reduce wages to compensate for an increase in payroll contributions in the short run (Gottret and Schieber, 2006). Therefore, payroll-financed health contributions may increase labour costs and, in turn, lead to higher unemployment. They may also reduce the competitiveness of the country and deter further investment.

\section{Widespread formal exemptions from the payment of social insurance contributions}

In addition to workers in the informal sector, many categories of labour force participants are exempt, by law, from paying contributions to health insurance funds. These groups may include both active labour market participants and inactive members of designated vulnerable groups such as the elderly and those with disabilities. In Albania, for example, the formally exempt categories of the population include pregnant women; war veterans; those with disabilities; the unemployed; recipients of social assistance; cancer patients; conscripts; and pensioners. In Bosnia and Herzegovina, pensioners, people with disabilities, the unemployed, refugees and people with foreign insurance are exempt.

These groups are exempt from making contributions but they are still entitled to the services that form part of the benefit package. The percentage of the population that falls into one of the exempt categories tends to be very large - in Bosnia and Herzegovina, for example, about half of those who are covered by health insurance are exempt from paying contributions - so there is a potential threat to the financial position of the fund. To cover the potential funding shortfall, the government typically undertakes to make contributions on behalf of these workers by way of transfers either from general revenues or from extra-budgetary funds (for example, from the pensions and unemployment funds). However, these contributions are not always designed to be equivalent in magnitude to the contributions rates paid through payroll taxation for health. Also, government ministries sometimes fail to fulfil their agreement to pay the defined contribution amounts for vulnerable groups that are exempt from contributions. This typically leaves health insurance funds facing deficits.

\section{Evasion of contribution payments}

Contributing to national health insurance funds is compulsory for most categories of employed and self-employed workers in the sub-region, but there is a risk that both employers and employees will evade contributions unless proper control mechanisms are in place.

For employers, high contribution rates create a strong incentive to avoid making contributions on their employees' behalf. In FYR of Macedonia, for example, where 
the employer bears the entire burden and, consequently, faces the highest employer contribution rates in the sub-region, it is estimated that, of the $8 \%$ of the population that do not contribute, most are formal sector workers whose employers fail to pay in contributions on their behalf.

For employees, the incentive to contribute depends not only on the contribution rate, but also on the size of the benefit package and the extent to which failure to contribute results in one being excluded from receiving benefits. Where benefit packages are less generous, the incentive to contribute to health insurance is small. In many countries, the link between contribution and entitlement is weak, while tax evasion is rife since those who evade contributions can still collect benefits. This is the case in Serbia where, despite a contributory social insurance system, there is, in practice, universal health coverage. In 2004, for example, the self-employed and farmers in Serbia contributed only $5 \%$ and $0.78 \%$ of total HIF revenues, far less than their population share.

Underlying tax evasion by both employers and employees are problems of information and enforcement. Those with incentives to evade taxes would not be able to do so if collection authorities could obtain information on evaders and enforce the payment of contributions. Most health insurance funds do not have information systems that would allow contributions to be linked to a beneficiary database. This limits their ability to control the collection of contributions and enforce payments from private employees, including the self-employed and farmers. Even if tax evaders could be identified, punitive measures are weak.

The incentives of the collecting agent also play a role in determining the extent to which the contribution of collections is enforced. In most countries in the sub-region, health insurance funds are the collecting agents. Bosnia and Herzegovina, however, has moved the collection function from the health insurance fund to the national tax authority. It is believed that this move substantially reduced the incentive to collect contributions because the link between collection efforts and revenues was broken (Langenbrunner et al, forthcoming). Furthermore, the taxation authority lacks the power and the inter-ministerial co-ordinating ability needed to impose sanctions on firms and workers that do not pay contributions. Recent data reveal that, in Bosnia and Herzegovina, collection rates vary from $30 \%$ to $84 \%$ between the cantons.

\section{Co-payment policies: widespread exemptions, low levels of co-payments and poor collection}

One source of revenue is charges levied at the point of service, whether these are copayments for services covered by health insurance, fees for services provided to those who are not covered by insurance, or fees for services that lie outside the benefit package. The purpose of such fees is generally two-fold: first, to generate revenue; and second, to curb excess demand for services by combating moral hazard.

Out of a concern for equity, the countries in the sub-region allow exemption from co-payments, or reduced co-payments, either through income testing or the categorical targeting of people who are more likely to be poor, such as the elderly. Exemptions from co-payments are also often introduced for particular categories of health services for which it is desirable to induce demand, such as immunisation, the treatment of infectious diseases and other preventive care. 
However, co-payment exemptions that are too widespread and co-payment levels that are too low may threaten the financial sustainability of health insurance funds and health systems. In FYR of Macedonia, it is estimated that, at any given time, almost $50 \%$ of the population is exempt from co-payments while in Serbia, prior to co-payment reform, about $65 \%$ of the population was exempt from co-payments although this has now been reduced to about $25 \%$ (through removing exemptions for the registered unemployed, most age-based exemptions and exemptions for particular categories of diseases).

In countries such as Macedonia and Albania, where health care providers are required to submit the co-payments that they collect to the health insurance funds, the poor revenue stream flowing from co-payments is further reduced by weak collection incentives. The budget of an individual institution is not affected by the volume of fees collected, so there is not a strong incentive to collect co-payments. Alternatively, it may create an incentive for the provider to collect, but not to remit, the fees. In Macedonia, for example, Health Insurance Fund (HIF) data show that only $8.1 \%$ of co-payments were remitted to the HIF, despite an actual collection rate of $96.4 \%$ of the co-payments that fell due. To align incentives better, Macedonia intended to change its policy from 1 January 2008 so that providers can keep co-payment income.

\section{Encouraging efficient expenditures}

Achieving health system objectives requires substantial expenditure. In order to contain these expenditures and maximise their impact, it is essential that money is spent efficiently.

In this section, we describe the current levels of health expenditure, trends in expenditure patterns and the allocation of expenditure across different health care categories. Then we discuss how the current levels of expenditure and particular patterns of allocation are driven by the mix of incentives created by the structure of the health care financing system such as, among other things, provider payment mechanisms, pharmaceutical procurement and pricing systems, the nature of the benefits package and the human resources policy.

\section{A large share of national resources are allocated to health care expenditure}

An analysis of health care expenditures in the western Balkans reveals that total health care expenditure (as a share of GDP) in the sub-region is similar to that in EU countries. However, the proportion of this expenditure that can be attributed to private spending is much larger than in the EU. Still, these expenditure levels translate into only small per capita levels of expenditure, even when the figures are adjusted for purchasing power parity. Also, aggregate public expenditure is in line with EU and EU-15 levels and per capita spending levels are low, but there is no fiscal space to increase public expenditures since health care already absorbs a large share of total government expenditure.

\section{Current expenditure levels as a share of GDP are aligned with EU countries}

The share of GDP allocated to health care by countries of the western Balkans tends to exceed that of most other lower-middle income countries and, instead, is on par with that of many EU members (see Figure 3). The total share of GDP spent on health 
care is lowest in Montenegro (6.6\%) and Albania (6.7\%), but health shares in FYR of Macedonia, Kosovo and in Bosnia and Herzegovina exceed the average expenditures of the EU-12. Total health expenditures, as a percentage of GDP, are highest of all in Serbia (10.6\%), exceeding the EU and EU-15 averages of $9.2 \%$ and $9.3 \%$ respectively.

Total health care expenditure in the sub-region is comparable to EU countries but the share of public expenditure is lower (with the exception of Serbia), meaning that private out-of-pocket expenditures account for an unusually high share of total expenditure - much more than in the European Union and comparator countries. Moreover, there is reason to believe that, at least in some cases, private health care expenditure in the sub-region tends to be under-estimated by official data. In FYR of Macedonia, for example, the use of Household Budget Survey data increases the estimate for private expenditure by a whole percentage point. This may be due, at least in part, to the incidence of informal payments as much as to the limitations of official data sources.

Across the sub-region there is a fair amount of variation in the mix of public and private expenditure. In FYR of Macedonia, Serbia and Montenegro, health expenditures are financed mainly from public sources, as in most other EU countries, whereas in Bosnia and Herzegovina public and private shares are very similar and, in Albania, private expenditures slightly exceed public expenditures.

Figure 3 - Total, public and private expenditure as a percentage of GDP, 2004

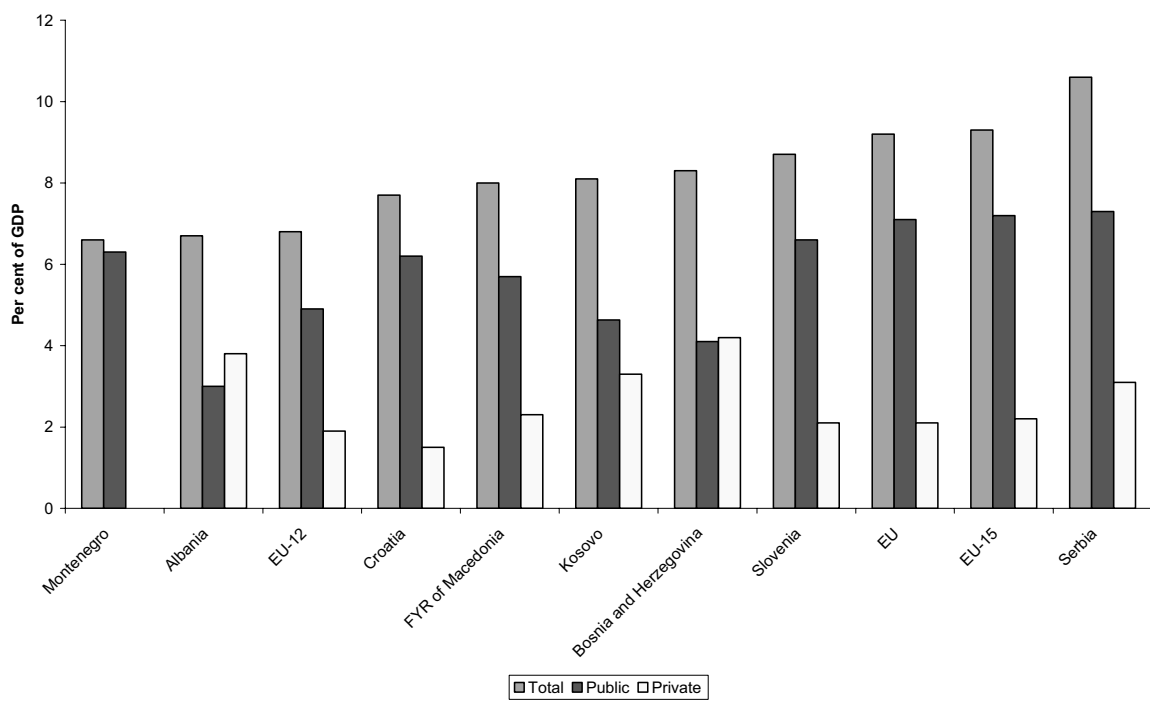

Source: WDI database 2007 for Albania, FYR of Macedonia, Bosnia and Herzegovina, Croatia, Slovenia and the EU aggregates; World Bank estimates for Serbia, Montenegro and Kosovo

Note: Data are ordered in ascending magnitude of total health expenditure; for Kosovo, 2004 levels are under-estimated due to the incomplete reporting of donor off-budget spending; EU aggregate data are GDP-weighted. 
Due to small per capita incomes, these high percentage expenditures translate into low levels of per capita expenditure (see Figure 4). In particular, in 2004 per capita expenditure in the western Balkan countries ranged from approximately $\$ 100$ (Kosovo) to $\$ 300$ (Serbia) expressed in terms of current US dollars. Expressed in PPPadjusted terms, this is equivalent to around $\$ 400$ (for those countries for which PPPadjusted data are available). Compared to levels in the rest of the European Union, per capita expenditure levels within the sub-region are very similar to each other.

Not only are per capita expenditure levels in the region fairly similar to each other in comparison to other countries, they are also very low. In 2004 dollar terms, per capita expenditure in the western Balkans in 2004 was less than one-tenth of that in countries in the European Union and less than one-half of that of the new EU entrants (i.e. the EU-12). Some share of the difference in expenditure levels between EU-15 countries and western Balkan countries can be explained by differences in purchasing power, but per capita expenditure figures for the countries of the sub-region remain around one-half of the average of the new EU entrants and about one-sixth of that of the EU-15, even when the figures are adjusted for purchasing power.

Figure 4 - Per capita health expenditure (in current US\$ and PPP\$), 2004; and change in per capita health expenditure (PPP\$), 1999-2004

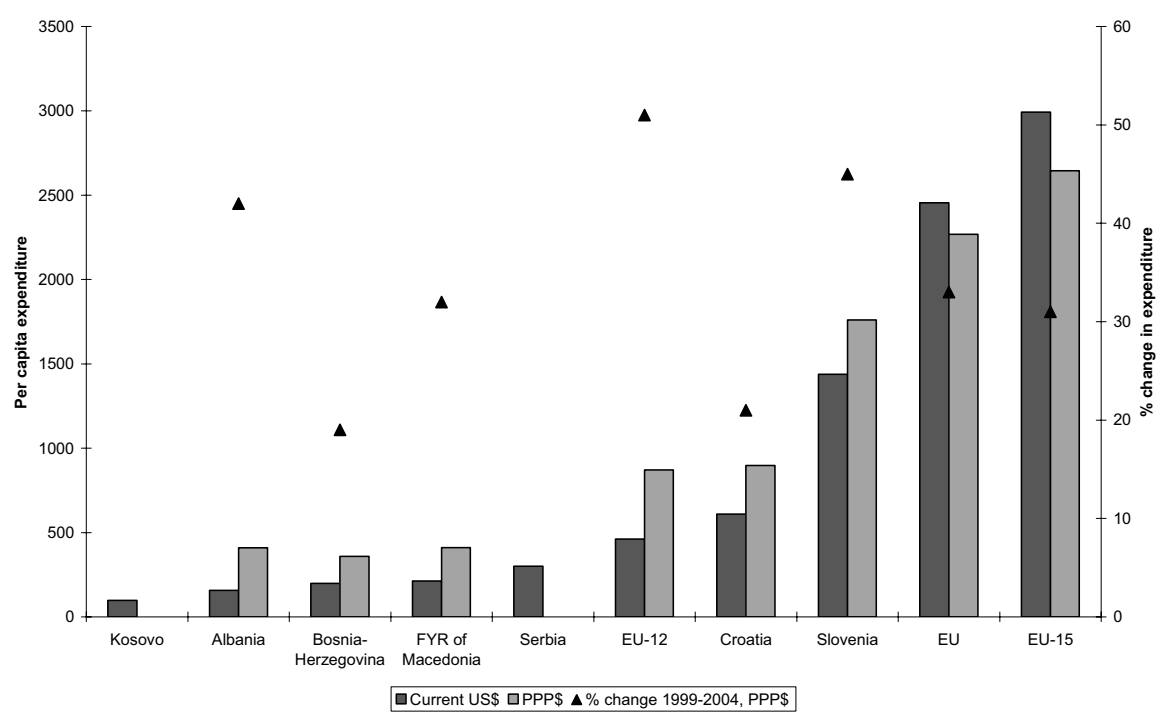

Source: WDI database 2007 for current US\$ figures and WHO HFA-DB 2007 for PPP\$ figures for Albania, FYR of Macedonia, Bosnia and Herzegovina, Croatia, Slovenia and the EU aggregates; World Bank estimates for Serbia and Kosovo

Note: Countries are ordered by increasing magnitude of per capita expenditure in current US\$; EU aggregates are population-weighted

Per capita expenditure levels have been increasing over time, however. With the exception of Bosnia and Herzegovina, the increase in PPP-adjusted per capita ex- 
penditure has either kept pace with or has exceeded the average EU increase of 33\% observed between 1999 and 2004. Still, increases are lower than the 51\% average increase observed across the new EU entrants.

The share of resources spent on health has not increased over the past decade The expenditure patterns described in the previous sections have had a certain amount of durability. Despite real total health expenditures having increased substantially over time, there is evidence of spending containment. With the exception of Albania, the rate of increase in health expenditures has been lower than the rate of growth in the economy and, when expressed as a percentage of GDP, total health expenditure in the sub-region has, in fact, fallen slightly over time. The downwards trend appears to have been equivalent to about one percentage point of GDP over the last decade. This is in contrast to the slightly increasing expenditures that have been observed in Slovenia and also elsewhere in the EU. Among the comparators, it is only in Croatia that health expenditures as a share of GDP have declined over the past decade (see Figure 5).

\section{The fiscal space to increase expenditures is extremely limited} Fiscal space can be defined as:

The capacity of government to provide additional budgetary resources for a desired purpose without any prejudice to the sustainability of its financial position. (Heller 2006)

Current per capita health care expenditure is low but it appears that - at least for the countries for which data are available - the fiscal space for additional expenditures on health is very limited. Most countries in the sub-region already spend a large proportion of their public budgets on health. In 2002, FYR of Macedonia and Serbia and Montenegro allocated the same share of government expenditure to health as Croatia and Slovenia (i.e. 14\%), even though the latter had tremendously higher levels of per capita expenditure (see Table 4). In addition, all countries in the sub-region spent the same, or a greater, share of total government expenditure on health as the EU-15. This means that, if health systems in the sub-region are to expand the quantity and quality of services offered to their populations, the resources for that will need to be sought either through:

a. sustained economic growth that generates formal employment and increases total public sector resource availability

b. increasing the cost-effectiveness and efficiency of the existing health sector programme.

It is only Albania that stands out in this respect, allocating half the budgetary share to health that other countries do. 
Figure 5 - Trends in total health expenditure (as percentage GDP) in the Western Balkans and comparator countries, 1996-2005

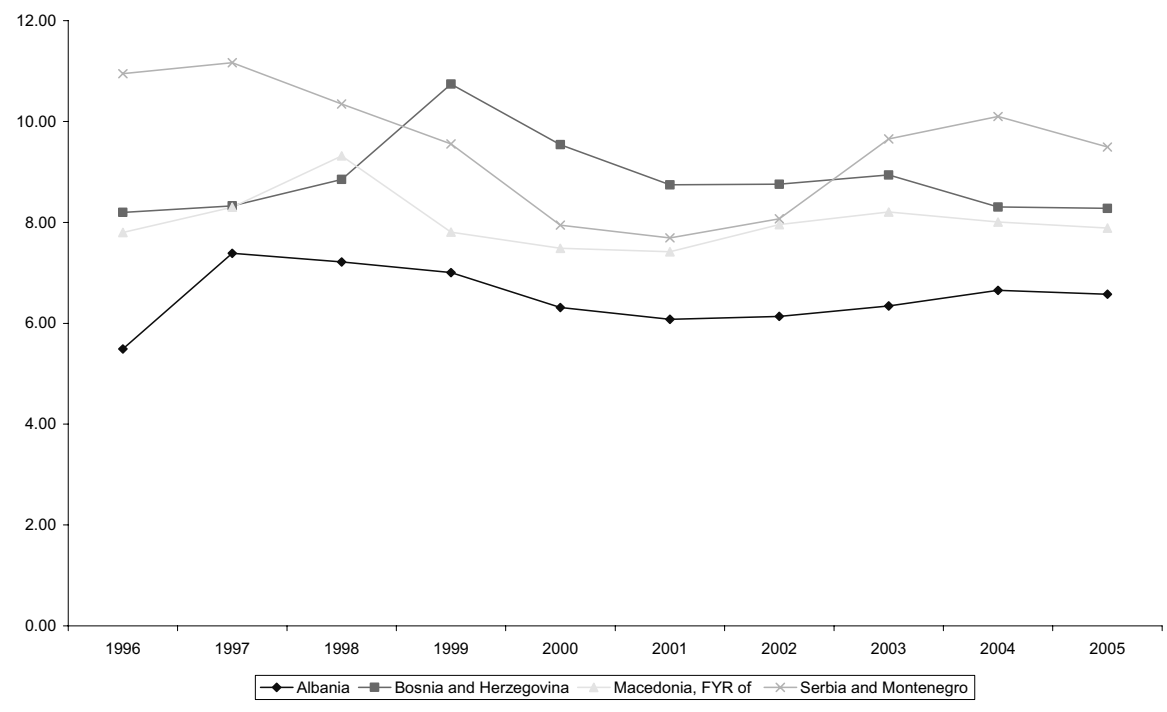

12.0

10.0

8.0

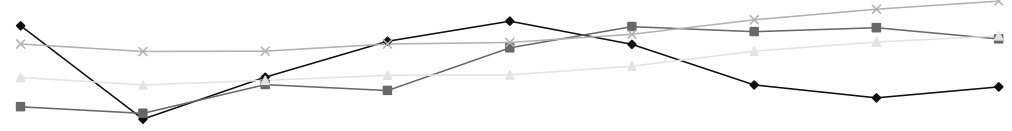

6.0

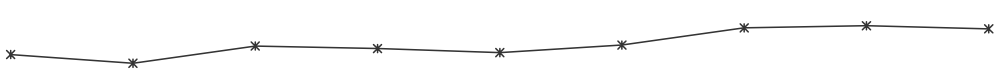

4.0

2.0

0.0

$1996 \quad 1997$

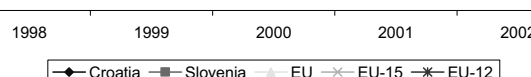

Source: WHO NHA database (for Western Balkans, Croatia and Slovenia) and WHO HFA-DB 2007 (for $E U, E U-15$ and $E U-12$ ) 
Table 4 - Public expenditure on health as a percentage of total government expenditure

\begin{tabular}{|l|c|c|}
\hline & Value & Year \\
\hline Albania & 7.3 & 2001 \\
\hline Bosnia and Herzegovina & 12.8 & Average of 1996-2002 \\
\hline FYR of Macedonia & 14.4 & Average of 1996-2002 \\
\hline Kosovo & 11.5 & Average of 2000-2002 \\
\hline Serbia and Montenegro & 14.0 & Average of 1996-2002 \\
\hline Croatia & 13.6 & Average of 1996-2002 \\
\hline Slovenia & 14.4 & Average of 1996-2002 \\
\hline EU-15 & 12.9 & \\
\hline
\end{tabular}

Source: IMF Government Finance Statistics; Bank estimates for Kosovo

The functional composition of public expenditure is marked by inefficiencies

Strict cross-country comparisons are not possible since categories of expenditure in the available data sources differ between countries, ${ }^{12}$ but it is clear that the composition of health care expenditure is skewed towards inpatient care. Typically, such an imbalance results in a crowding-out of expenditure on outpatient and preventive care - care that is typically more cost-effective. Still, the ratio of inpatient to outpatient care, in most cases, is not that much higher than in the EU-15 and OECD countries. In terms of the percentage of total public spending on health, the EU-15 spends about $38 \%$ on inpatient care and $31 \%$ on outpatient care. The ratio is identical in OECD countries which, on average, allocate most of their health expenditure to inpatient care $(38 \%)$, followed by outpatient services including ancillary services and homecare $(31 \%)$ (Orosz and Morgan, 2004). Very similar ratios are observed in the Federation of Bosnia and Herzegovina and in Montenegro. In FYR of Macedonia and Republika Srpska, however, the percentage of the budget of the health insurance fund spent on inpatient care is almost ten percentage points higher than in the EU-15 and in other countries of the sub-region.

Pharmaceutical expenditures are also very high and an important driver of medical inflation (see next section). ${ }^{13}$ Also, actual total expenditure on drugs are higher than these figures reveal because most pharmaceutical estimates tend to reflect only outpatient and retail pharmacy drug expenditure, not the large drug expenditures that

12 This reflects differences in national health accounting systems, since the standard National Health Accounts expenditure reporting methodology is not yet used in most of the countries of the sub-region. The one exception is Serbia, where a first set of national health accounts have recently been completed, although the process is yet to be institutionalised.

13 See the Policy Note on the Pharmaceutical Sector in the Western Balkans for a more indepth description of the expected increase in spending on pharmaceuticals in the sub-region in the next few years. 
are incurred while in hospital and which are classified as part of inpatient care expenditure.

A conclusive statement can not be made, since data are not available for all countries, but capital expenditures in the sub-region tend to be lower than required to maintain the physical infrastructure and medical equipment in good condition and to purchase up-to-date medical technology.

Table 5 - Health insurance fund expenditures by level of care, 2002-2004 (\%)

\begin{tabular}{|l|c|c|c|c|}
\hline & Inpatient & Outpatient & $\begin{array}{c}\text { Prescription } \\
\text { drugs }\end{array}$ & $\begin{array}{c}\text { Capital } \\
\text { investment }\end{array}$ \\
\hline Bosnia and Herzegovina & & & & \\
\hline 口 Federation & 38 & 31 & 7 & 5 \\
\hline - Republika Srpska & 51 & 27 & 7 & 2 \\
\hline FYR of Macedonia & 50 & 19 & 13 & 0.36 \\
\hline Montenegro & 39 & 30 & 12 & 4 \\
\hline Serbia & 41 & 24 & 12 & 0.30 \\
\hline Croatia & 45 & 16 & 13 & n.a. \\
\hline Slovenia & n.a. & n.a. & n.a. & n.a. \\
\hline EU-15 & $38^{\mathrm{a}}$ & 31 & n.a. & n.a. \\
\hline
\end{tabular}

Sources: Original data from Health in Transition Reports, OECD health data and Bank estimates

Note: EU-15 figure refers to expenditures on inpatient care as a percentage of total public spending on health, and not as a percentage of heath insurance fund expenditure.

\section{Expenditures have to be better managed to avoid the accumulation of deficits}

There has been some improvement in recent years, but in most countries in the sub-region, health insurance funds continue to incur repeated deficits which, over the years, have resulted in large arrears for the public health sector. Many health care institutions are also in arrears, with substantial accumulated debts to their suppliers.

For example, in Bosnia and Herzegovina, arrears in the health sector amounted to $0.9 \%$ of GDP in 2004. Arrears were equivalent to $0.5 \%$ of GDP in the Federation, but were more acute in Republika Srpska where, at $1.9 \%$ of GDP, they were equivalent to almost one-third of public health spending. By far the major share of arrears was incurred by hospitals.

In FYR of Macedonia, there has been a substantial reduction in arrears as a result of the introduction of measures such as monthly financial reporting by the health insurance fund and health care institutions; competitive bidding to improve efficiency in the procurement of pharmaceuticals; and hard budget ceilings for health care institutions. By the end of July 2006, total arrears were approximately $\$ 78 \mathrm{~m}$, which is a $23 \%$ reduction on the figures for the preceding year. Of the total still owed, $66 \%$ arises from the debts of health care institutions and the rest from debts of the health insurance fund. 
Serbia has also had persistent health sector deficits, with the arrears of the HIF growing from 7.9 billion dinars in 2002 to 9.5 billion dinars by the end of 2004. During this period, debts to health care institutions increased until they constituted almost one-half of all the debts of the health insurance fund. Other arrears in the health insurance fund include accumulated debts in the form of delayed sick leave payments to beneficiaries and interest payments (equivalent to $3 \%$ of total HIF expenditures). In 2006, all arrears were paid off - in a one-off transfer - out of the proceeds of privatisation. Such solutions do not address the underlying causes of the problem, even though they do provide temporary deficit relief.

Montenegro is the one country that has increasingly managed to bring annual health insurance fund deficits under control. It has progressively improved the financial position of its health insurance fund, from a deficit of over $8 \%$ at the end of 2001 to a $1 \%$ surplus in 2004 .

\section{Drivers of health expenditure}

The data presented in the previous section showed that total health expenditure in the region is lower than in the EU in per capita terms, but that it is not substantially lower in terms of GDP. This means that there is unlikely to be room to increase expenditures, in spite of the low per capita spending levels and the poorer health status indicators. Rather, spending on any priority areas will need to be financed from efficiency gains and savings in current areas of health care expenditure rather than from additional budgetary allocations to health.

In this section, we examine the main drivers of health care expenditure in the subregion, with a specific focus on how to improve the efficiency of those expenditures. In particular, we look at the upward pressures on health care expenditure that are brought to bear by the current health care financing arrangements and the behavioural incentives that they have created.

\section{Pharmaceutical procurement and pricing systems}

The countries of the western Balkans spend between $12 \%$ and $24 \%$ of their public health expenditure on pharmaceuticals. On a per capita basis, there is much variation in annual expenditure levels, ranging from less than $\$ 30$ per year in Albania to around $\$ 60$ in Serbia, Montenegro and FYR of Macedonia. ${ }^{14}$ These levels are not excessive compared to expenditure levels in OECD countries, where public expenditure on pharmaceuticals and medical devices averages $21 \%$ of public health expenditures (Orosz and Morgan, 2004), but the current procurement and pricing systems result in a number of inefficiencies which drive up costs unnecessarily. In the future, the upwards pressure on pharmaceutical expenditures may be further aggravated by the aging of the population (if one consequence of aging is that the elderly will have a greater number of unhealthy life years than they have now), increases in the utilisation of the health system (which is one of the goals of health system reform programmes in the region), and the development of new, potentially more expensive, pharmaceuticals.

14 These figures have not been adjusted for purchasing power parity and, if they were, there is likely to be less variation between countries. 
The drug pricing and procurement system has implications not only for the share of pharmaceuticals in health insurance fund expenditures (i.e. for public expenditure) but also for household out-of-pocket expenditure on health. Pharmaceutical expenditures account for a large share of households' private expenditure on health. According to FYR of Macedonia's 2005 Household Budget Survey, for example, pharmaceuticals constitute the largest component of household expenditure on health (followed by spending on medical services), accounting for three-quarters of the health expenditures of the lower four quintiles. Poor supply management in pharmaceuticals in the public health system can aggravate the situation where it results in drug shortages in the public sector and drugs have to be purchased from private pharmacies. In Kosovo, for example, households spend an average of $65 \%$ of their out-ofpocket health expenditure on purchasing drugs that are supposed to be provided free under Kosovo's essential drug programme but which are not available in public health centres or hospital pharmacies.

\section{Figure 6 - Pharmaceutical expenditure in the public health sector as a percentage of total public spending on health, and per capita pharmaceutical expenditures}

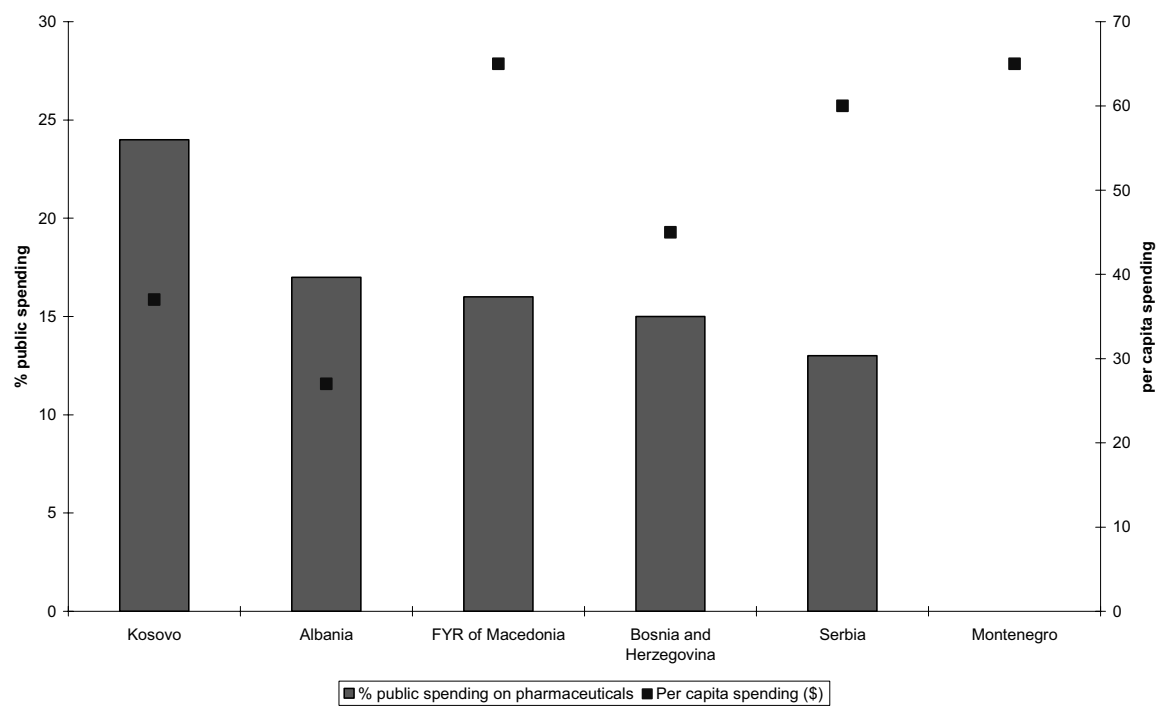

Source: World Bank estimates (for expenditure as a percentage of GDP) and discussions with stakeholders (for per capita figures, see Policy Note on the Pharmaceutical Sector in the Western Balkans)

Note: For expenditure as a percentage of GDP: data are for the most recent year available, usually 2004 or 2005; data for Bosnia and Herzegovina reflect total pharmaceutical expenditure as a percentage of total health expenditure; part of the variation in expenditure levels between countries may be attributable to differences in definitions of pharmaceuticals; data refer to 'prescription drugs' in Albania and Serbia, and only to outpatient pharmaceuticals and devices in Macedonia and in Bosnia and Herzegovina, excluding drugs used in inpatient care. In terms of per capita expenditure: the figure for Bosnia and Herzegovina provided by stakeholders is 'less than 50' rather than an actual number. 
There are many measures that countries in the western Balkans could consider to improve the efficiency of their pharmaceutical sectors. These include both supplyside mechanisms (e.g. price controls, positive lists, pre-approval for expensive drugs, competitive procurement and volume controls) and demand-side mechanisms (e.g. co-payment for prescription drugs and budget or quota restrictions for physicians).

If efficiency gains are to be realised and expenditure contained, an important starting point is to ensure that positive lists of those drugs that are covered by health insurance funds have been developed. The decision to include new drugs on positive lists should only be taken after careful economic analysis of the cost-effectiveness of those medications. Guidelines to help providers prescribe drugs on the positive list should be laid down and pharmacists could be encouraged to substitute prescribed drugs for generic equivalents included on the list. Where higher cost brands (of noninnovative drugs) are preferred by the consumer or provider, health insurance funds should limit reimbursement to the lowest generic equivalent or, at the very least, impose higher co-payments.

How drugs are priced is a key driver of pharmaceutical expenditures. Prices for most medicines in the western Balkans tend to be regulated. For single-source patented drugs, reference pricing schemes are in place that set a domestic price based on the prices (typically, the lowest prices) in neighbouring countries and some EU countries. Countries with reference pricing should ensure that this system is used for the entire set of patented drugs included on the positive list. For generic drugs, prices tend to be negotiated with the manufacturer, and so competition among manufacturers in the procurement of drugs could be more actively encouraged. One approach could be to use competitive tender mechanisms in defining the prices of drugs on the positive list. This strategy has enabled Serbia, Montenegro and FYR of Macedonia to reduce drug prices in the public sector substantially. Montenegro's Health Insurance Fund, for example, spent an enormous $30 \%$ of total health expenditures on pharmaceuticals in 2002 but, following the introduction of a sophisticated pharmaceuticals information system and an open tender system, managed to reduce drugs costs by $31 \%$ within two years. The introduction of competitive bidding for pharmaceuticals in Macedonia is reported to have contributed to a $30 \%$ decline in pharmaceutical expenditures. One canton in Bosnia and Herzegovina, Tuzla, has also introduced an open tender system.

The regulation of pharmacies needs to be strengthened and measures should be taken to enhance transparency in their pricing systems. High mark-ups on drugs at the pharmacy level are common and are often in excess of the levels recommended by health ministries. For example, Republika Srpska uses a system of reference prices based on generic drug level to define sales prices for HIF-reimbursable drugs, but pharmacies then sell drugs at prices that are about three times above the Ministry of Health's suggested prices. The implementation of a sophisticated pharmaceuticals information system that links health insurance funds to pharmacies and allows health insurance funds to monitor expenditures, such as is in place in Montenegro, could yield substantial dividends. Introducing better drug labelling systems could help to combat illegal imports and overcharging by pharmacies. A major reform in Albania, for example, was to introduce labels that show the retail price, name of the drug, the importer and the batch number.

The decentralisation and fragmentation that characterises the health care system in Bosnia and Herzegovina imposes additional costs. There, each of the thirteen health 
insurance funds (including the FBH Solidarity HIF and the twelve cantonal HIFs) has its own drug procurement rules, procedures and positive lists. Small procurement volumes with high associated transaction costs result in substantially higher prices. There are also sharp geographic inequalities since prices often differ substantially between cantons while some cantons are too poor to pay for the more advanced drugs. In the $\mathrm{FBH}$, a price-setting system that selects preferred manufacturers and wholesalers in the cantons results in a substantial geographic price variation under which co-payments for the same drugs may vary between $25 \%$ and $100 \%$ of drug prices between the cantons and the entities. Substantial efficiency gains, which would be translated into cost savings, could be realised if a single competitive procurement process and a single positive list was established at a more central level, possibly through the creation of one centralised drug agency or, at the very least, one drug agency at each entity level.

Finally, in order properly to track pharmaceutical expenditures, countries should strengthen their national health accounts systems. Currently, it is only expenditure on pharmaceuticals provided by public outpatient providers and reimbursed through the HIF that can be accurately monitored. Expenditure on inpatient drugs is usually not counted as pharmaceutical expenditure but, rather, is included together with inpatient costs under 'inpatient expenditures', resulting in an under-estimation of total pharmaceutical expenditures. Also, measuring out-of-pocket expenditure on any aspect of healthcare is almost impossible without regular, and detailed, household budget surveys.

\section{Generous benefit packages and increasingly expensive medical technology}

In the Socialist Federal Republic of Yugoslavia (SFRY), access to health care was a constitutional entitlement of all citizens and benefits were exceptionally comprehensive. Today, health care benefits at both primary and secondary level remain very generous in Serbia, Montenegro, Kosovo, Macedonia and in Bosnia and Herzegovina, and typically include a range of non-essential services and even non-health benefits. This tends to drive up expenditures by encouraging excessive consumption of these services, which are often very expensive.

In Serbia, recent reforms have eliminated coverage for plastic surgery and funeral expenses, and restricted dental coverage to children, but the package still includes expensive treatment abroad and generous sick leave benefits. There is anecdotal evidence that the sick leave provision is frequently abused and used to disguise redundant unemployment temporarily. In Macedonia, the non-medical benefits of maternity leave and sick leave consume as much as 5-6\% of annual HIF expenditures. By contrast, in Albania, which does not have the same legacy of generous health insurancerelated entitlements, the benefit package is more limited.

In all countries, there is a risk that the benefit package will expand in size over time: advances in medical technology mean there will be a demand for the inclusion of the latest technological procedures in the benefit package. This demand will come not only from consumers but also from health care providers, especially those who have benefited from more sophisticated training and continuing medical education.

Consequently, countries in the region need to move towards defining affordable benefit packages that are focused on services provided at the primary and secondary 
level. This process will require a careful analysis of the costs, and cost-effectiveness, of different treatments and a careful analysis of anticipated health insurance revenues.

One reform that countries could consider would be to remove non-medical benefits from the health insurance package. These benefits are not included in most EU countries and, in comparisons of health care expenditure, artificially inflate the share of GDP devoted to health in the western Balkans. The difference, in the case of Serbia for example, is estimated to be equivalent to around $1 \%$ of GDP.

With respect to new technologies, it may be prudent for countries in the sub-region to follow the example of many EU countries and adopt formalised medical technology assessment (MTA) and pharma-economics techniques in evaluating the cost-effectiveness of new technologies prior to giving approval for their inclusion in benefits packages. Currently, decisions tend to be made by committees of experts which are typically dominated by clinicians rather than financing specialists. This could occur in conjunction with reforms that reserve investment in the most sophisticated medical technology for tertiary and specialised hospitals, and that implement appropriate referral systems to ensure that those patients who need the particular technology receive it. This could help to prevent unnecessary duplication of equipment and technological investment that is not justified by patient loads.

\section{Salaries}

Expenditure on medical and non-medical wages and salaries accounts for a fairly large share of total health expenditure, but the share varies widely across the sub-region. The wage bill accounted for $48 \%$ of public expenditure on health in the Federation of Bosnia and Herzegovina in 2006 (World Bank estimates), a similar share in Republika Srpska in 2004 (World Bank estimates), 46\% in Macedonia in 2005 (WHO HFA-DB 2007), 29\% in Serbia and in Montenegro in 2000 (WHO HFA-DB 2007) and $35 \%$ in Kosovo ${ }^{15}$ (World Bank estimates). By comparison, the wage bill was equivalent to $35 \%$ of public expenditure on health in the EU-12 countries in 2004 (WHO HFA-DB).

That salaries account for such a large share of total health expenditure means that they are an important determinant of the financial sustainability of health systems. Adopting a sustainable human resource strategy needs to be an explicit question addressed by ministries of health if costs are to be contained. The size of the wage bill is determined both by the number of employees in the health sector and by their wages.

Recent data reveal that the number of physicians, and especially the number of nurses, is lower per capita in the western Balkans than in EU-15 and EU-12 countries, despite the high share of salaries in total public expenditure on health. In Albania and in Bosnia and Herzegovina, the density of doctors is especially low, at less than half EU levels. The problem is not the total number of physicians but the excessive proportion of specialists. This is because, in the past, there was a tendency to train too many specialist doctors and too few general practitioners, which shifts expenditures upwards by providing specialised care to patients who could be treated more cost-effectively at lower levels of care. In Serbia, for example, two-thirds of medical doctors are specialists and only $15 \%$ are general practitioners. The cost-effectiveness of the

15 The Kosovo figure is, in fact, very high if one considers that highly-specialised care is not offered in the province. 
health care systems of the western Balkans could be improved by following the OECD practice of increasing the number of nurses relative to doctors and allowing nurses to undertake a wider range of clinical functions combined with selective referral to specialists. An examination of the data shows that doctor:nurse ratios are not, in fact, higher in the western Balkans than in EU countries, but nurses in the sub-region do often perform a range of ancillary rather than clinical functions and their numbers are not, therefore, representative of medical and clinical capacity.

\section{Figure 7 - Staff resources, 2005}

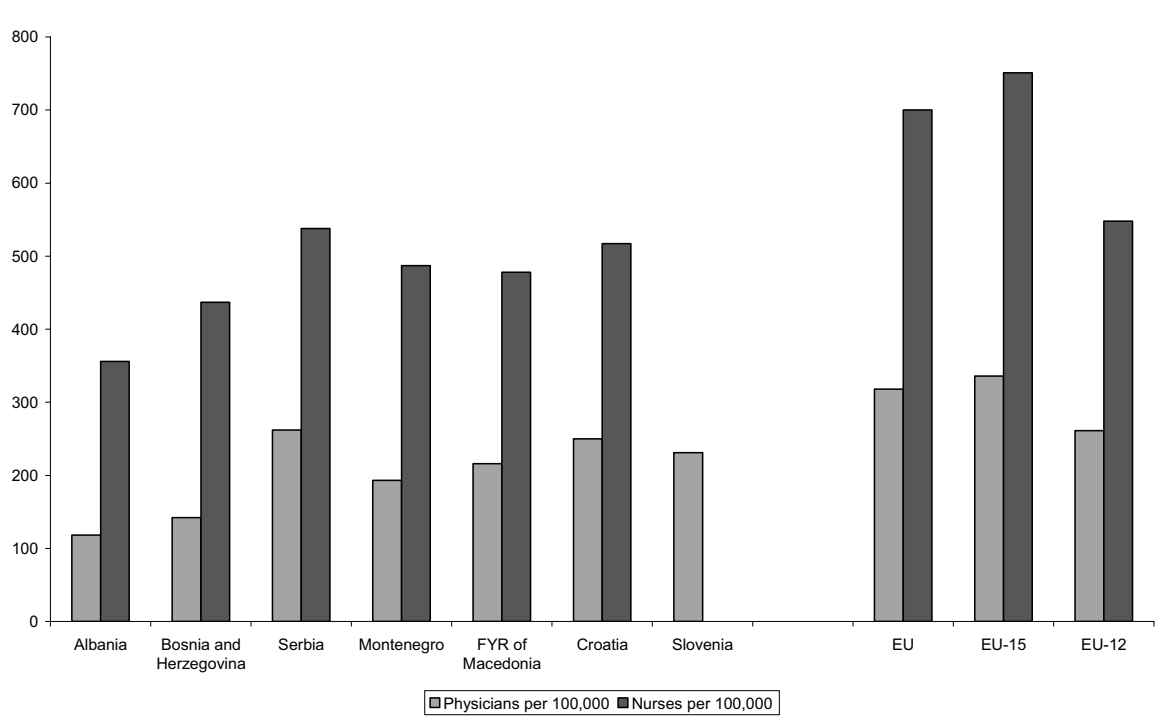

Source: WHO HFA-DB, 2007

Note: Data are for 2005, except for the EU-15 and Slovenia where data are for 2004.

There is an expectation that there will, in future, be a demand for higher salaries, especially among doctors. Wage compression across different medical professions (e.g. doctors, nurses, specialists) is typical in the western Balkans and means that doctors' salaries are among the lowest in Europe, which fuels wage demands and creates an incentive for doctors to emigrate. Thus, expenditure on wages, as a percentage of public spending on health, is already close to EU levels - but future upwards pressure on the wage bill is expected. The example of the EU-8 countries may be instructive: between 1999 and 2003, the average monthly salary in the Czech Republic, Slovakia and Hungary increased by more than the average monthly salary of occupational groups with equivalent levels of education and experience (Chawla, 2005). Moreover, the ratio of physician salaries to the national average for these occupational groups in the western Balkans is well below the average ratio of 2 that may be observed in EU15 countries.

Another source of upwards pressure on the wage bill is a staffing structure that exhibits large ratios of non-medical (i.e. ancillary) to medical staff. In Macedonia, for 
example, non-medical staff account for almost $30 \%$ of total staff numbers; in Bosnia and Herzegovina, the figure is $33 \%$. The share is slightly lower, at around $28 \%$, in Serbia and Montenegro, and is being further reduced under current reform programmes, but is still high compared to the ratios in the EU and comparator countries. In the United Kingdom, for example, the figure is only $13 \%$. However, the functions of many ancillary staff working in the United Kingdom and other European health systems tend to be contracted out, so this figure is likely substantially to under-estimate the number of ancillary workers in the public health care sector in such countries, thus making it very difficult accurately to gauge the extent to which the non-medical to medical staff ratio in the western Balkans really exceeds that of the EU.

Improving the efficiency of the health sector will necessarily involve a rationalisation of the number and type of workers in the health sector, as well as of their functions. Serbia, for example, has already taken steps to reduce the number of medical and non-medical employees as part of a wider public sector rationalisation programme.

Optimising the staff mix could be facilitated by moving from an input-based hospital payment method to an output-based one. The fixed annual budget allocations of input-based systems mean that health care managers have neither the autonomy and flexibility, nor the incentives, to hire and fire workers so as to optimise the staff mix.

\section{Excess medical capacity in the hospital sector}

The share of health expenditure devoted to the hospital sector in the western Balkans is high but the sector is marked by low productivity. This takes a number of forms.

Inpatient admission rates are low with the result that available resources, such as hospitals, beds and staff, are under-utilised. Annual inpatient admission rates range from 8.7 per 100 people in Albania to 12 per 100 people in Serbia, compared to 17 in Croatia, 18 in Slovenia, 17 in the EU and 21 in the EU-12. Bed occupancy rates in acute care hospitals for those countries for which data are available (i.e. Serbia, Montenegro and Macedonia) are between five and ten percentage points lower than the EU average of $76 \%$. Moreover, patients who are admitted seem to have longer than average stays in hospital, of between 9.5 and 11 days, compared to an average of 8 days in the EU-10 and 9.25 days in the EU as a whole. This means that bed occupancy rates are higher than they would have been were patients being discharged or moved to outpatient care as soon as they could be. Only in Albania is the average length of stay (ALOS) very short, about 6.4 days. Comparison with data from earlier years suggests, however, that the ALOS has been rapidly decreasing: between 2000 and 2005, the ALOS fell by at least one day in all the countries of the western Balkans.

With the exception of Montenegro, the number of outpatient contacts per person per year is low compared to EU countries. In Albania, the average person utilises outpatient care only about 1.5 times per year. This number is higher in Bosnia and Herzegovina (3.3) and in FYR of Macedonia but is well below the EU and Montenegro average of around 7. 
Table 6 - Inpatient and outpatient health care utilisation, 2005 (unless noted otherwise)

\begin{tabular}{|l|c|c|c|c|}
\hline & $\begin{array}{c}\text { Bed occupancy } \\
\text { rates } \\
\text { (acute care } \\
\text { hospitals) }\end{array}$ & $\begin{array}{c}\text { ALOS } \\
\text { (days) }\end{array}$ & $\begin{array}{c}\text { Inpatient } \\
\text { admissions, } \\
\text { per 100 people }\end{array}$ & $\begin{array}{c}\text { Outpatient } \\
\text { contacts, } \\
\text { per person } \\
\text { per year }\end{array}$ \\
\hline Albania & - & 6.4 & 8.7 & 1.5 \\
\hline Bosnia and Herzegovina & - & 9.6 & 8.2 & 3.3 \\
\hline Serbia & $69 \% *$ & 10.6 & 12.0 & - \\
\hline Montenegro & $69.7 \% *$ & $9 . *^{*}$ & 10.7 & 6.9 \\
\hline FYR of Macedonia & $55.5 \%$ & 11.1 & 9.9 & 4.3 \\
\hline Kosovo & - & - & - & - \\
\hline Croatia & $88.1 \%$ & 10.3 & 16.6 & 6.9 \\
\hline Slovenia & $70.1 \%$ & 7.1 & 17.6 & 7.2 \\
\hline EU & $75.9 \%$ & $9.3^{*}$ & $18.1 *$ & $6.8^{*}$ \\
\hline EU-15 & - & $9.6^{* *}$ & $17.5^{* *}$ & - \\
\hline EU-12 & $74 \%$ & 8.03 & 20.8 & 7.9 \\
\hline
\end{tabular}

Source: WHO HFA-DB, 2007, except for Serbia and Montenegro (World Bank estimates)

Note: Data are for 2005, unless denoted by an * for 2004 or a ** for 2003.

With the exception of Macedonia, all countries have between one and two hospitals per 100000 people, compared to an average of three in the EU. Also, compared to the EU average of 585 beds per 100000 population, the number of beds in the hospital sectors of the western Balkans is not completely excessive and is actually much lower than the group of new EU entrants, where the average was 644 per 100000 in 2005 (see Table 7). In fact, the number of beds per 100000 people in Albania and in Bosnia and Herzegovina is about half that of the EU. Moreover, it is only in Serbia and in Bosnia and Herzegovina that health systems seem to be dominated by a few large hospitals with enormous bed capacity. Elsewhere, capacity is very similar to the $\mathrm{EU}$ - at least, on a population-wide basis.

What may be more of an issue is the appropriateness of the distribution of those beds across hospital sectors (general, specialised and tertiary care) and across the geographic area of the country. Bed numbers in specialised facilities may not necessarily correspond to the specific medical needs of the population; bed numbers may not be located in the areas of greatest population need, while other population groups may have access to a number of medical facilities. In urban centres, for example, there are some very large hospitals that account for a large share of total national bed availability, but there is very little access in rural areas. For example, Macedonia averages 470 
beds per 100000 people, but the distribution of these beds is such that bed capacity varies between 130 per 100000 in Kochani and 520 per 100000 in Shtip.

Another major source of inefficiency in health systems is the loss of productivity that can result due to the under-utilisation of primary health care facilities, too-frequent referral from the primary care level to the secondary and tertiary care levels and the skipping of primary care treatment in order to seek care directly at the secondary and tertiary level. Physicians in Bosnia and Herzegovina, for example, only resolve about half of primary health care cases and refer the rest to more expensive secondary and tertiary care, even though such referrals may be unnecessary. One contributing factor is the low number of primary health care units in some countries. In Bosnia and Herzegovina, Serbia and Montenegro, the number of primary health care units per 100000 people is only around 30, which is half as many as there are in the EU-12 countries.

Table 7 - Supply of medical facilities, 2005

\begin{tabular}{|l|c|c|c|}
\hline & $\begin{array}{c}\text { Hospitals } \\
\text { per 100 000 }\end{array}$ & $\begin{array}{c}\text { Primary health care } \\
\text { units per 100 000 }\end{array}$ & $\begin{array}{c}\text { Hospital beds } \\
\text { per 100 000 }\end{array}$ \\
\hline Albania & 1.6 & 76.55 & 297 \\
\hline Bosnia and Herzegovina & 0.95 & 30.28 & 304 \\
\hline Serbia & 1.38 & - & 593 \\
\hline Montenegro & 1.93 & 29.52 & 418 \\
\hline Macedonia, FYR & 2.65 & 91.05 & 470 \\
\hline Kosovo & - & - & - \\
\hline Croatia & 1.76 & 74.54 & 483 \\
\hline Slovenia & 1.45 & 3.2 & 585 \\
\hline EU & 3.04 & - & 571 \\
\hline EU-15 & 3.19 & - & 644 \\
\hline EU-12 & 2.63 & 62.22 & 483 \\
\hline
\end{tabular}

Source: WHO HFA-DB, 2007

Note: Data are for 2005, except for the EU-15 data which are for 2004.

To improve hospital productivity, the average length of stay (ALOS) should be shortened, bed occupancy rates increased and the number of beds reduced. Further reductions may be possible by improving admission management, facilitating earlier discharge and strengthening co-ordination among levels of providers, especially when it comes to moving patients from inpatient to outpatient care.

Countries could also consider reducing the number of beds and planning better so that the number of hospitals and beds is based on the estimated catchment-area population. Moving to a case-based payment method is one possible way to achieve a more 
rational allocation of beds since hospitals without sufficient cases would be forced to merge with other hospitals or close down. Standards of care and decision rules that help to reduce the average length of stay in hospitals could be implemented.

\section{Line budgeting}

Current systems of paying providers, and especially hospitals, neither encourage cost containment nor provide incentives for better performance. It is these systems that are, in part, responsible for the efficiency problems, such as excess medical capacity and excess staff, discussed in the previous sections.

In the sub-region, line budgeting is still the most common provider payment mechanism. In this system, the health insurance fund pays providers according to line items, such as wages and salaries, utilities, medicines and other supplies, on the basis of an annual contract negotiated between the health insurance fund and each provider. The budget in one year is largely determined by the costs of inputs in the previous year, so hospital management has an incentive to utilise the entire budget each year rather than to contain expenditures. Also, contracts between health care institutions and health insurance funds may require reports on performance, but there are typically no penalties associated with poor performance and, hence, no accountability. In addition, the budget is related to historical patterns and not to the number and severity of cases treated, so there is no incentive to treat difficult cases, but rather an incentive to refer them to higher levels of care. This means that primary care providers do not act as effective gate-keepers to higher levels of care.

In the medium-term, countries in the region could consider moving from inputbased to output-based financing mechanisms. A useful starting point may be the implementation of global budgeting, which is currently under development in Bosnia and Herzegovina and FYR of Macedonia. This is a prospective budget-setting approach that fixes the price as well as the volume of inpatient services. A more sophisticated provider payment mechanism would be the use of case-based financing based on diagnosis-related groups (DRGs). Most countries in western Europe now use a combination of global budgeting and the DRG approach, and a pilot is currently underway in Podgorica, Montenegro.

Such reforms will necessarily have to be accompanied by capacity-building in health information systems in order to capture the data necessary to make informed decisions about the allocation of resources. For global budgeting, and especially for a DRG approach, detailed information on the costs of all the different resources, as well as data on the different diagnostic groups, will be needed.

\section{Moving forward}

Over the past decade, all countries of the sub-region have embarked on a number of reforms aimed at improving access to a health system that provides comprehensive quality services and protects vulnerable groups from the impoverishing effects of illhealth, while still ensuring the systems' fiscal sustainability. Experience elsewhere in Europe has shown that such reforms are technically, institutionally and politically difficult and need to be sustained for extended periods if they are to be implemented effectively (Belli, 2001). Clearly, there is no 'one size fits all' solution and devising strategies to manage health care expenditures will require careful consideration of the precise financing mechanisms in place, the macroeconomic context and the political 
climate. However, the following actions can be singled out as necessary elements of a successful reform.

\section{Optimise revenue collection}

The sustainability of health care systems depends largely on the ability to generate sufficient revenues. Today, many countries in the western Balkans continue to face difficulties in raising revenues due to high levels of unemployment, informal economic activity and poor collection mechanisms. In countries with social health insurance, the aging of the population will put increasing pressure on the sustainability of health financing both through increased demand for health care by the adult population and, most importantly, larger dependency ratios and a smaller contribution base. Many countries in Europe that relied on payroll contributions alone to finance health care have begun to revisit their financing arrangements and, to different degrees, have started to rely more on general revenues. Depending on their institutional and fiscal situation, and on their preferences, countries in the western Balkans should also develop an explicit, comprehensive revenue collection strategy that considers all available methods such as direct taxation, indirect taxation, social security contributions, voluntary health insurance and user charges. ${ }^{16}$

\section{Rationalise the benefit package}

In all western Balkan countries, benefit packages are very comprehensive and, therefore, very costly. In order to eliminate the implicit rationing of health care stemming from an unaffordable benefit package - and the associated inefficiencies and inequities - it is necessary to align the services provided with the resources that are available. This process should involve a review of the size and scope of the package that takes into consideration international practice, national demographic and epidemiological characteristics and the expected future flow of revenues.

\section{Modernise the health care delivery system}

The introduction of a new primary health care model that emphasises family medicine is proving to be successful in most countries and is resulting in increased patient satisfaction. This should be just the first step, however, towards a more profound re-organisation process aimed at, eventually, making general practitioners the 'gatekeepers' of the rest of the health system as part of a wider strategy of optimising the existing network of providers. In order to do so, most countries in the western Balkans have started to prepare hospital restructuring strategies (also referred to as master plans) to re-orient the delivery system towards preventive and primary care and to increase the efficiency of the hospital network by establishing infrastructure, equipment, staffing and service standards in each facility. Politically, this is a very difficult process and is often in conflict with the interests of physicians who tend to be specialists working in larger hospitals.

16 See Langenbrunner et al. (forthcoming) for a discussion on the options for sources of health financing and revenue collection. 


\section{Engage the private sector}

Involving the private sector in both the financing and provision of health care services needs to be further explored because of the potential efficiency gains and greater consumer choice it offers. Involvement can include the provision of private health care in public or private facilities which will, in turn, require a stronger role for government in licensing, accreditation and quality assurance. Private health insurance, either as a substitute or complement to social health insurance, exists only in Serbia. Public-private partnerships are not yet well-known in the sub-region. There is substantial scope for private sector involvement in health care financing and delivery, but successful involvement will require the careful development of an appropriate legal and regulatory framework. This is an issue that needs to be integrated into the greater debate on health care reforms in the western Balkans.

\section{Strengthen human resource planning and training}

Important as the financing and organisational reforms are, countries also need to proceed quickly to upgrade the clinical management of care. To do so, two types of interventions are particularly important. First, providers' skills ought to be upgraded to reflect state-of-the art medical practice, which relies heavily on evidence-based medical and nursing practices. Second, new protocols ought to be developed since some of the existing ones are outdated, especially with regard to the promotion of healthy lifestyles, the prevention of non-communicable diseases and outpatient-based methods of disease management. Continuing medical education, which has been introduced as part of the health system reforms in most countries of the western Balkans, needs to be sustained.

\section{Reform the payment system for health providers}

The payment system that countries in the western Balkans have inherited pays salaries that are based on coefficients defined by the ministry of health in collaboration with the ministry of finance and trade unions of health care professionals. The system does not grant any substantial financial incentive for the accomplishment of a greater volume of work and/or for the delivery of more efficient and better quality services. Changing the way health care providers are paid is the central pillar in re-orienting the health system away from historical, line item budgeting towards a system that rewards outputs and quality, thereby increasing the efficiency of public spending and the sustainability of health financing.

Reforming the payment system will, however, be a very difficult and lengthy process. One of the biggest constraints is the limited capacity for strategic purchasing in most health insurance funds. Most countries in the western Balkans have started, or plan to start, introducing capitation payments for primary health care and case-based payments for secondary and tertiary care. Along with countries starting to change provider payment mechanisms, it is crucial to consider individual incentives as well as institutional ones. It is not sufficient to devise ever more sophisticated reimbursement systems at the institutional level if employees within those institutions continue to receive the same low, productivity-independent salaries. In addition, steps will need to be taken to reduce the volume of informal payments made to health care providers since they undermine the impact of health reforms, siphon funds away from the health 
system and negatively affect the quality of service provided to those who cannot, or do not, make these payments.

\section{Regulate the pharmaceutical sector}

Countries in the western Balkans have made significant progress in modernising their pharmaceutical sectors. Nevertheless, drug expenditure is set to grow in this region as it did in other countries in eastern Europe, typically at a rate of about twice GDP growth, due to inevitable factors such as innovation, aging populations, increasing incomes and better access to health care. For the foreseeable future, there will be a need for further capacity-building in the pharmaceutical sector, with a focus on increased oversight and higher professional standards, more efficient use of limited public resources, better drug pricing policies, equity in access and the rational use of medicines.

\section{Improve data quality}

The paucity of good data with which to track health care expenditure and revenue streams, and analyse liabilities, deficits and arrears, is a constraint on countries' abilities to manage their expenditures effectively. An important first step could be to move towards institutionalising systems of national health accounts within each country, which would allow the analysis of expenditure by combinations of provider type, function and financing source. In the western Balkans, it is only Serbia that is advanced in this process, although the first steps towards it have been taken in Montenegro and Kosovo. At the level of the individual institutions, the establishment of formal and regular financial reporting mechanisms is important. Regular household budget surveys with detailed health budget components would greatly enhance the measurement of private out-of-pocket health expenditures.

So far, governments in the sub-region have managed to contain the increases in public spending on health within the rate of growth of their economies. At the same time, not only does the fiscal space further to increase public spending on health remain limited, but health insurance funds have generally failed to keep their expenditures in balance with their revenues while the health system has accumulated substantial debt. If the desired goals of the health system are to be achieved, health system reforms will need to be sustained for extended periods of time. Thus, the western Balkans no longer face the choice of either reforming their health sectors or leaving them unchanged; fiscal pressures make sectoral change inevitable. The real question is whether policy-makers will allow change to occur in a piecemeal fashion toward uncertain outcomes, or whether they will instead try to steer it along a sustainable path.

\section{References}

Belli, P (2001) Ten years of health reforms in the ECA region Harvard Center for Population and Development Studies working paper series 11(6).

Chawla, M (2005) Managing health expenditures in the new EU member states: options for reforms unpublished manuscript.

Heller, P (2006) 'The prospects of creating 'fiscal space' for the health sector' Health Policy and Planning 21(2): 75-79. 
Langenbrunner, J. C, I. Sheiman and J. Kehler (forthcoming) pre-publication draft 'Chapter Six: Sources of health financing and revenue collection: reforms, lessons and challenges' Approaching health financing policy in the WHO European region expected publication by EU Health Observatory, 2007.

Orosz, E and D. Morgan (2004) SHA-Based National Health Accounts in Thirteen OECD Countries: A Comparative Analysis OECD Health Working Papers 16, OECD Directorate for Employment, Labour and Social Affairs.

Sanigest Health Solutions (2006) Serbia Hospital Payment Reform Project consultant report, 22 December 2006.

WHO/EURO (2006) Approaching health financing policy in the WHO European Region paper prepared for the fifty-sixth session of the Regional Committee for Europe.

WHO HFA-DB database http://www.euro.who.int/hfadb

WHO NHA database http://www.who.int/nha/en/

World Bank (2006) From red to gray: the 'third transition' of aging populations in Eastern Europe and the Former Soviet Union Washington, D.C: World Bank.

\section{Appendix}

Table 8 - Share of health care financing derived from different sources

\begin{tabular}{|c|c|c|c|c|c|c|}
\hline & \multicolumn{2}{|c|}{ Public } & \multicolumn{3}{|c|}{ Private } & \multirow[t]{2}{*}{ Total } \\
\hline & SHI & $\begin{array}{l}\text { General } \\
\text { revenues }\end{array}$ & OOP & $\begin{array}{c}\text { Private in- } \\
\text { surance }\end{array}$ & NGOs & \\
\hline \multicolumn{7}{|l|}{ Western Balkans } \\
\hline Albania & 10.8 & 32.7 & 56.4 & 0.0 & 0.1 & 100 \\
\hline Bosnia and Herzegovina & 46.6 & 2.1 & 51.2 & 0.0 & 0.0 & 100 \\
\hline Kosovo & 0 & 59.0 & 61.0 & 0.0 & 0.0 & 100 \\
\hline FYR of Macedonia & 67.9 & 2.7 & 29.4 & 0.0 & 0.0 & 100 \\
\hline Serbia and Montenegro & 52.6 & 16.9 & 27.6 & 2.9 & 0.0 & 100 \\
\hline \multicolumn{7}{|l|}{ Comparators } \\
\hline Croatia & 71.9 & 9.5 & 17.5 & 1.1 & 0.0 & 100 \\
\hline Slovenia & 70.4 & 6.6 & 10.0 & 13.0 & 0.0 & 100 \\
\hline
\end{tabular}

Source: WHO NHA database

Note: The definition of 'private insurance' includes all pre-paid, private risk-pooling plans; Kosovo data are for 2004 and the figure does not show the $2.1 \%$ of donor funding received in that year. 